\title{
Avaliação funcional e histológica da tireoide de ovinos suplementados com fluoreto de sódio por um período de 150 dias
}

\author{
[Functional and histological evaluations of thyroid of sheep submitted \\ to sodium fluoride administration ] \\ D.S. Prestes, A. Filappi, D.R. Schossler, F.A. Duarte, V.L. Dressler, \\ E.M.M. Flores, M. Cecim ${ }^{*}$ \\ Universidade Federal de Santa Maria \\ Av. Roraima, 1000 - Camobi \\ 97105-900, Santa Maria, RS
}

\begin{abstract}
RESUMO
Avaliou-se o efeito da administração de fluoreto de sódio sobre a tireoide de 12 ovinos, distribuídos em dois grupos: o grupo controle $(\mathrm{n}=6)$ recebeu somente sal iodado ( $5 \mathrm{~g} \mathrm{de} \mathrm{NaCl} /$ animal $+0,2 \mathrm{ppm} \mathrm{I} / \mathrm{kg} \mathrm{MS})$ e o grupo tratado $(\mathrm{n}=6)$, sal iodado $(5 \mathrm{~g}$ de $\mathrm{NaCl} / \mathrm{animal}+0,2 \mathrm{ppm} \mathrm{I} / \mathrm{kg} \mathrm{MS})$ adicionado de fluoreto de sódio (4,7mg F/kg de peso corporal), durante 150 dias. Amostras de sangue foram coletadas para análise sérica de I e F, triiodotironina $\left(\mathrm{T}_{3}\right)$ e tetraiodotironina $\left(\mathrm{T}_{4}\right)$ nos dias zero, 60, 90 e 150 de tratamento. Também se coletou urina, correspondente às 24 horas, para análise da excreção urinária de I e F. Após a eutanásia dos animais, a tireoide foi removida para posterior exame. Quanto ao I urinário, não foi observada diferença estatística entre os grupos controle e tratado e dentro de cada grupo, entre os tempos. As concentrações de $\mathrm{T}_{3}$ e $\mathrm{T}_{4}$ não diferiram entre os grupos e dentro de cada grupo nos diferentes tempos. Quanto à avaliação histopatológica da tireoide, não foram observadas alterações na integridade estrutural. Conclui-se que a administração crônica de fluoreto de sódio não interfere na função e na integridade histológica da glândula tireoide de ovinos com dieta não restritiva de iodo.
\end{abstract}

Palavras-chave: ovelha, flúor, histologia, hormônios

\begin{abstract}
The effect of sodium fluoride administration on thyroid function and morphology in sheep was evaluated using 12 lambs. Animals were allotted in two groups: control that received $5 \mathrm{~g} \mathrm{NaCl}+0.2 \mathrm{ppm} \mathrm{I/kg} \mathrm{DM}$ and treated which received the same treatment plus sodium fluoride $(4.7 \mathrm{mg} \mathrm{F} / \mathrm{kg} \mathrm{BW}$ ), daily, for 150 days. Blood samples were collected for determination of $F, I, T_{3}$, and $T_{4}$. Urine production was collected for measurement of $F$ and I. After euthanasia at 150 days of treatment, thyroid glands were removed for analysis. No differences were found between or within groups for urinary I. Also, no differences were found for $T_{3}$ and $T_{4}$ on serum I between groups or among time points. No histological alterations were found in the thyroids. In conclusion, chronic sodium fluoride treatment did not affect thyroid function and morphology in lambs.
\end{abstract}

Keywords: sheep, fluoride, histology, hormones

\section{INTRODUÇÃO}

O flúor (F) é um elemento essencial para a saúde (McDowell, 1999), porém é requerido em quantidades extremamente baixas, não havendo citação específica de um teor mínimo para animais de produção. A administração de $\mathrm{F}$ resulta em sua absorção e em seu transporte, via corrente sanguínea, para os tecidos e órgãos, podendo causar mudanças estruturais e

Recebido em 4 de agosto de 2008

Aceito em 9 de março de 2009

* Autor para correspondência (corresponding author)

E-mail:mcecim@smail.ufsm.br 
funcionais (Cenesiz et al., 2005). Anke et al. (1997) relataram a presença de deformidades esqueléticas em cabras e baixo crescimento de sua prole quando esses animais foram submetidos a dietas contendo $<0,3 \mathrm{mg} \mathrm{F} / \mathrm{kg}$ de matéria seca. Contudo, alterações metabólicas têm sido mais associadas ao consumo elevado desse elemento ( $\mathrm{Li}, 2003$ ).

Há relatos da ação antagônica do $\mathrm{F}$ sobre o sistema nervoso (Li, 2003; Zengrong et al., 2008), sobre o sistema reprodutivo (Al-Hiyasat et al., 2000) e também sobre o metabolismo tireoideano (Mahmood Bhat, 1996; Zhao et al., 1998). A tireoide é responsável pela produção dos hormônios triiodotironina $\left(\mathrm{T}_{3}\right)$ e tiroxina $\left(\mathrm{T}_{4}\right)$, cuja síntese depende do iodo (I) (McDowell, 1999). Burgi et al. (1984) mencionaram que uma dose de $\mathrm{F}$ acima da recomendada para a prevenção de cáries foi capaz de inibir várias etapas da biossíntese dos hormônios tireoideanos em animais experimentais. Zhao et al. (1998) observaram que o excesso de $\mathrm{F}$, em ratos, é capaz de induzir a mudanças funcionais e histológicas na tireoide.

Para ruminantes, criados em regime extensivo, a fonte mais comum de $\mathrm{F}$ advém da suplementação mineral, na qual se apresenta como contaminante, sobretudo em fontes de fósforo como o fosfato de rocha (Lopes, 2001). Cabe ressaltar que a tolerância ao $\mathrm{F}$ varia conforme as espécies animais. Segundo McDowell (1999), ovinos adultos podem receber até $150 \mathrm{ppm}$ de $\mathrm{F}$ na dieta, sem que haja efeito sobre seu desempenho. Quanto ao I, a obrigatoriedade de sua adição ao sal acabou por restringir as investigações acerca da deficiência desse elemento.

Em animais de produção, poucos estudos têm sido realizados sobre a influência do flúor sobre o metabolismo animal. Assim, o objetivo do presente estudo foi avaliar o efeito da administração de fluoreto de sódio, por um período de 150 dias, na função e histologia da glândula tireoide de ovinos com dieta não restritiva de iodo.

\section{MATERIAL E MÉTODOS}

O experimento foi realizado no período de novembro de 2005 a abril de 2006. Foram utilizados 12 ovinos, machos, inteiros, raça Texel x Ile de France, idade aproximada de cinco meses, pesando entre $33-40 \mathrm{~kg}$. Durante o período experimental, os animais foram mantidos em baias e receberam como dieta diária $3 \%$ do peso vivo de feno de alfafa e água ad libitum. Após um período de adaptação de 15 dias, os animais foram distribuídos em dois grupos de seis ovinos cada. $\mathrm{O}$ grupo controle recebeu sal iodado $(5 \mathrm{~g}$ de $\mathrm{NaCl} /$ animal $+0,2 \mathrm{ppm} \mathrm{I} / \mathrm{kg}$ MS) e o grupo tratado, sal iodado $(5 \mathrm{~g}$ de $\mathrm{NaCl} /$ animal $+0,2 \mathrm{ppm}$ $\mathrm{I} / \mathrm{kg} \mathrm{MS})$ adicionado de fluoreto de sódio $(4,7 \mathrm{mg}$ $\mathrm{F} / \mathrm{kg}$ de peso corporal). Em ambos os grupos, o conteúdo foi diluído em água destilada, administrado via sonda oroesofágica, diariamente, por um período de 150 dias. A fonte de iodo utilizada foi iodato de potássio. Mensalmente, amostras do feno de alfafa e de água foram coletadas para análise de F e I. Quinzenalmente, os ovinos foram avaliados clinicamente quanto ao aspecto dentário para verificar possíveis alterações características de fluorose.

Amostras de sangue sem anticoagulante foram coletadas no dia zero e aos 60,90,120 e 150 dias de tratamento para análise sérica de I e $\mathrm{F}$ e concentrações dos hormônios triiodotironina $\left(\mathrm{T}_{3}\right)$ e tetraiodotironina $\left(\mathrm{T}_{4}\right)$. Ainda, nesses tempos, os animais foram alojados em gaiolas metabólicas para obtenção de urina correspondente às 24 horas. Nessas amostras foi mensurada a taxa de excreção urinária de I e F. As concentrações séricas $\mathrm{T}_{3}$ e $\mathrm{T}_{4}$ foram mensuradas pelo método de quimioluminescência. O I sérico e urinário foi determinado por meio de espectrometria de emissão ótica com plasma indutivamente acoplado (ICP-OES). As concentrações de F nas amostras séricas e urinárias foram detectadas potenciometricamente por meio de íon eletrodo seletivo. A preparação das amostras séricas e urinárias para análise de I e F foram efetuadas de acordo com técnica recomendada por Eaton et al. (1995).

Após a eutanásia dos animais, a glândula tireoide foi removida e fixada em solução de Bouin's para posterior exame histológico e morfométrico. As lâminas foram coradas com hematoxilinaeosina. A histomorfometria da tireoide foi efetuada mediante análise do diâmetro folicular e da altura do epitélio basal dos folículos, conforme técnica recomendada por Luna (1968). Esse procedimento foi realizado com ocular micrométrica por meio de microscópio de luz. 
Consideraram-se para a medição 10 estruturas histológicas (com repetição), sendo que a leitura foi efetuada em cinco campos (aumento de 100x), totalizando 100 estruturas analisadas.

Os resultados foram expressos em média \pm desvio-padrão. A significância da diferença entre as médias foi determinada mediante a análise de variância, e o valor de $\mathrm{P}<0,05$ foi considerado significante. Para análise histológica, utilizou-se teste $\mathrm{t}$.

A metodologia utilizada foi aprovada pela Comissão de Ética e Biossegurança da Universidade Federal de Santa Maria sob o parecer no 49/2007, e os estudos com os animais foram realizados de acordo com normas éticas.

\section{RESULTADOS E DISCUSSÃO}

A dosagem de $\mathrm{F}$ utilizada neste experimento $(4,7 \mathrm{mg} / \mathrm{kg}$ de peso vivo) foi selecionada porque em estudo prévio com ovinos (Kessabi et al., 1986) foi capaz de produzir elevação nos teores de $\mathrm{F}$ nos dentes e ossos. Quanto à análise da alimentação ofertada aos animais, foram observadas concentrações traços de F e I, não representando fontes significativas desses elementos na dieta.

As concentrações urinárias de $\mathrm{F}$ e $\mathrm{I}$ são apresentadas na Tab. 1. Em relação à concentração urinária de $\mathrm{F}$, houve diferença $(\mathrm{P}<0,001)$ entre os grupos, sendo observados teores mais elevados no grupo tratado. Nesse grupo ainda houve diferença $(\mathrm{P}<0,01)$ entre os tempos de 60, 120 e 150 dias, sendo verificada a maior concentração de $\mathrm{F}$ urinário ao final do experimento. Esse resultado pode ser compreendido, pois, segundo McDowell (1992), a eliminação do $\mathrm{F}$ absorvido ocorre quase que exclusivamente via urinária, e o incremento dessa excreção é diretamente proporcional ao aporte de F na dieta. De acordo com os dados mencionados por Shupe (1980) para bovinos e por Samal e Naik (1992) para ovinos, os animais deste experimento se enquadrariam em um caso de fluorose moderada a severa. No entanto, durante este experimento, nas avaliações clínicas quanto ao aspecto dentário, não foram observadas alterações características de fluorose, apesar de as concentrações urinárias de F serem condizentes com aquelas verificadas neste quadro.

Tabela 1. Média \pm desvio-padrão de iodo $(\mathrm{I})$ e flúor $(\mathrm{F})$ na urina de ovinos que receberam iodato de potássio (0,2ppm I/kg de matéria seca), tratados ou não com fluoreto de sódio $(4,7 \mathrm{mg} \mathrm{F} / \mathrm{kg}$ de peso corporal)

\begin{tabular}{ccccccc}
\hline & & \multicolumn{5}{c}{ Dias de tratamento } \\
\cline { 3 - 7 } & Grupo & zero & 60 & 90 & 120 & 150 \\
\hline I & Controle & $2,66 \pm 0,53$ & $2,66 \pm 1,09$ & $4,08 \pm 1,50$ & $3,55 \pm 0,56$ & $3,44 \pm 1,25$ \\
$(\mathrm{mg} / \mathrm{L})$ & Tratado & $3,74 \pm 1,10$ & $2,77 \pm 1,22$ & $4,30 \pm 1,50$ & $3,32 \pm 1,00$ & $3,87 \pm 1,22$ \\
\hline F & Controle & $0,60 \pm 0,23$ & $0,44 \pm 0,10^{*}$ & $0,80 \pm 0,43^{*}$ & $0,90 \pm 0,23^{*}$ & $0,68 \pm 0,17^{*}$ \\
$(\mathrm{mg} / \mathrm{L})$ & Tratado & $0,45 \pm 0,07 \mathrm{a}$ & $18,04 \pm 3,58 \mathrm{~b}$ & $22,30 \pm 4,75 \mathrm{bc}$ & $27,79 \pm 6,79 \mathrm{c}$ & $29,77 \pm 8,26 \mathrm{c}$ \\
\hline
\end{tabular}

Letras diferentes indicam diferença significativa $(\mathrm{P}<0,05)$ entre médias nos Asterisco $(*)$ indica diferença significativa $(\mathrm{P}<0,05)$ entre grupo-controle e tratado.

Quanto ao I urinário, não foi observada diferença estatística entre os grupos-controle e tratado e dentro de cada grupo, entre os períodos.

As concentrações séricas de $T_{3}, T_{4}$ e $I$ não diferiram entre os grupos e, dentro de cada grupo, nos diferentes tempos de tratamento. Em relação à concentração sérica de $\mathrm{F}$, houve diferença $(\mathrm{P}<0,001)$ entre os grupos. Nos animais do grupo tratado, a concentração se manteve maior, em todos os tempos avaliados. Entre tempos, não foi observada diferença estatística (Tab. 2).

Quanto à avaliação histológica da glândula tireoide, não foram observadas alterações na integridade estrutural do órgão nos animais de ambos os grupos. Em relação ao estudo morfométrico, também não foi observada diferença estatística no tamanho dos folículos e na altura do epitélio basal entre os gruposcontrole e tratado. 
Tabela 2. Média \pm desvio-padrão de triiodotironina $\left(\mathrm{T}_{3}\right)$, tiroxina $\left(\mathrm{T}_{4}\right)$, iodo $(\mathrm{I})$ e flúor $(\mathrm{F})$ no soro de ovinos que receberam iodato de potássio $(0,2 \mathrm{ppm} \mathrm{I} / \mathrm{kg}$ de matéria seca), tratados ou não com fluoreto de sódio $(4,7 \mathrm{mg} \mathrm{F} / \mathrm{kg}$ de peso corporal)

\begin{tabular}{ccccccc}
\hline & Grupo & \multicolumn{5}{c}{ Dias de tratamento } \\
\cline { 3 - 7 } & & zero & 60 & 90 & 120 & 150 \\
\hline $\mathrm{T}_{3}$ & Controle & $156,87 \pm 54,04$ & - & $95,16 \pm 11,84$ & $57,82 \pm 9,18$ & $124,49 \pm 48,32$ \\
$(\mathrm{ng} / \mathrm{dL})$ & Tratado & $152,92 \pm 75,51$ & - & $108,95 \pm 36,31$ & $66,04 \pm 17,18$ & $138,01 \pm 43,77$ \\
\hline $\mathrm{T}_{4}$ & Controle & $8,73 \pm 2,19$ & - & $4,74 \pm 1,48$ & $4,62 \pm 0,32$ & $6,00 \pm 1,10$ \\
$(\mu \mathrm{g} / \mathrm{dL})$ & Tratado & $8,57 \pm 2,81$ & - & $4,15 \pm 1,15$ & $5,78 \pm 0,84$ & $8,04 \pm 0,94$ \\
\hline $\mathrm{I}$ & Controle & - & $1,60 \pm 0,68$ & $1,85 \pm 1,55$ & $1,54 \pm 1,31$ & $0,96 \pm 0,50$ \\
$(\mathrm{mg} / \mathrm{L})$ & Tratado & - & $1,20 \pm 0,66$ & $0,93 \pm 0,51$ & $0,72 \pm 0,36$ & $0,50 \pm 0,30$ \\
\hline $\mathrm{F}$ & Controle & - & $0,16 \pm 00,3 \mathrm{a}$ & $0,10 \pm 0,01 \mathrm{a}$ & $0,15 \pm 0,02 \mathrm{a}$ & $0,12 \pm 0,02 \mathrm{a}$ \\
$(\mathrm{mg} / \mathrm{L})$ & Tratado & - & $0,41 \pm 0,10 \mathrm{~b}$ & $0,38 \pm 0,05 \mathrm{~b}$ & $0,38 \pm 0,08 \mathrm{~b}$ & $0,39 \pm 0,08 \mathrm{~b}$ \\
\hline
\end{tabular}

Letras diferentes indicam diferença significativa $(\mathrm{P}<0,05)$ entre grupo-controle e tratado

O aumento observado nas concentrações séricas e urinárias de $\mathrm{F}$, no grupo tratado é um indicativo de que houve eficiente absorção desse elemento, sendo observadas concentrações elevadas em relação ao grupo-controle. A ingestão contínua de F também foi capaz de elevar os teores séricos e plasmáticos deste elemento, em animais de outros estudos (Samal e Naik 1992; Humberto, 2007). Contudo, no presente experimento, não foram observados quaisquer sinais indicativos de fluorose. Quanto ao I, as concentrações séricas e urinárias mantiveram-se constantes durante todo o período experimental, demonstrando que não houve interferência na absorção desse elemento pelo F. Cabe ressaltar que tanto para o $\mathrm{F}$ como para o I, a principal via de excreção é a urinária. Geralmente, o status nutricional de I é estimado por meio de sua excreção urinária total em 24 horas (Soldin, 2002).

Neste estudo, os valores observados nas concentrações séricas de $\mathrm{T}_{3}$ e $\mathrm{T}_{4}$ foram constantes, em ambos os grupos. Segundo McDowell (1992), a concentração sérica de $T_{4}$ aliada à avaliação histológica da tireoide são dados importantes para auxiliar no diagnóstico da deficiência leve de I. A concentração sérica de $\mathrm{T}_{4}$ se manteve próxima a $6,05 \mu \mathrm{g} / \mathrm{dL}$, citada como referência para espécie ovina (Kaneco, 1997).

Todos os animais do experimento receberam I em doses iguais e dentro do intervalo de referência para a espécie, de $0,1-0,8 \mathrm{mg} / \mathrm{kg}$ de matéria seca, conforme recomenda o NRC (Nutrient..., 1985). A constância nos resultados encontrados pode estar associada ao fato de que, segundo Galletti e Joyet (1958), o F não impede a capacidade da glândula tireoide de sintetizar os hormônios tireoideanos, quando o I estiver em concentrações adequadas no sangue. Assim, a toxicidade do F dependerá da oferta de I.

Mecanismos de ação do F sobre a glândula tireoide sugeridos em diferentes estudos incluem o decréscimo na síntese dos hormônios tireoideanos, efeitos no transporte desses hormônios no sangue e efeitos na conversão periférica de $T_{4}$ para $T_{3}$ ou no processo normal de deiodinação (Larsen e Davies, 2002; Goodman, 2003). Segundo Tezelmann et al. (1994), o F, mediante o incremento intracelular na concentração de monofosfato de adenosina cíclico (cAMP), pode causar desensibilização dos receptores tireoideanos ao estímulo gerado pelo hormônio estimulante da tireoide (TSH). Rezende et al. (1999), em estudo com frangos de corte, verificaram influência da alta ingestão de F sobre a produção de cAMP hepático, havendo elevação.

Willem et al. (1972) demonstraram que o NaF deprime a endocitose do coloide e secreção da tireoide, por meio da inibição da glicólise aeróbica, na célula folicular. No estudo realizado por Swarup et al. (1998) verificou-se que na deiodinação houve efeito inibitório do F sobre a atividade da deiodinase, incluindo decréscimo das concentrações plasmáticas de $\mathrm{T}_{3}$ e teores normais ou elevados de $\mathrm{T}_{4}$ e TSH. Outros relatos incluem concentrações normais de $\mathrm{T}_{3}$ e elevadas de $\mathrm{T}_{4}$ (Lin-Fa-Fu et al., 1991; Sucheela et al., 2005) ou, ainda, decréscimo dos teores de $\mathrm{T}_{3}$ e $\mathrm{T}_{4}$ (Hillman et al., 1979; Marasli, 1992; Cinar e Selcuk, 2006). Larsen e Davies (2002) comentaram que, em vários experimentos com animais, tanto os efeitos periféricos como os efeitos diretos do F sobre a glândula tireoide, por vezes, tornam-se difíceis de serem estimados 
com exatidão, devido à dificuldade de realização de exames, como exemplo, cita a medição do TSH.

Neste estudo, não foram observadas alterações histológicas e morfométricas na glândula tireoide dos ovinos tratados com NaF. Em experimentos realizados com roedores (Mahmood Bhat, 1996; Bouaziz et al., 2005), visando avaliar o efeito de $\mathrm{NaF}$ sobre a integridade estrutural da glândula tireoide, observaram-se alterações caracterizadas por degeneração gordurosa no tecido conectivo interfolicular, hiperplasia das células foliculares, incremento no número de folículos e de sua vascularização e decréscimo de coloide

\section{CONCLUSÃO}

A administração crônica de fluoreto de sódio não interfere na função e na integridade histológica da glândula tireoide de ovinos com dieta não restritiva de iodo

\section{REFERÊNCIAS BIBLIOGRÁFICAS}

ANKE, M.; GURTLER, H.; NEUDERT, H. et al. Effects of fluoride-poor diet in generation of goat. In: FISCHER, T.W.S.; L'ABBÉ, M.R.; COCKELL, K.A. et al. In: SYMPOSIUM ON TRACE ELEMENTS IN MAN AND ANIMALS, 9., 1997, Ottawa. Proceeding.... Ottawa: NRC Research, 1997. p.192-194.

AL-HIYASAT, A.S.; ELBETIEHA, A.M.; DARMANI, H. Reproductive toxic effects of ingestion of sodium fluoride in female rats. Fluoride, v.33, p.79-84, 2000.

BOUAZIZ, H.; SOUSSIA, L.; GUEMAZI, F. et al. Fluoride-induced thyroid proliferative changes and their reversal in female mice and their pups. Fluoride, v.38, p.185-192, 2005.

BURGI, H.; SIEBENHUNER, L.; MILONI, E. Fluorine and thyroid gland function: a review of the literature. Klin Wochenschr., v.62, p.564-569, 1984.

CENESIZ, S.; OZCAN, A.; KAYA, N. et al. Chronic effects of fluoride in Tuj sheep on serum levels of total protein, albumin, uric acid and nitric oxide and activities of lactate dehydrogenase and leucine aminopeptidase. Fluoride, v.38, p.52-56, 2005.

CINAR, A.; SELCUK, M. Effects of chronic fluorosis on thyroxine, triiodothyronine, and protein-bound iodine in cows. Fluoride, v.38, p.6568, 2006.
EATON A.D.; CLESCERI, L.S.; GREENBERG, A.E. et al. Standard methods for the examination of water an wastewater. Washington: APHA, 1995. $1018 \mathrm{p}$.

GALLETTI, P.M.; JOYET, G. Effect of fluorine on thyroidal iodine metabolism in hyperthyroidism. $J$. Clin. Endocrinol. Metab., v.18, p.1102-1110, 1958.

GOODMAN, H.M. Basic medical endocrinology. 3.ed. San Diego: Academic, 2003.

HILLMAN, D.; BOLENBAUGH, D.L.; CONVEY, E.M. Hipothyroidism and anemia related to fluoride in dairy cattle. J. Dairy Sci., v.62, p.416-423, 1979.

HUMBERTO, H.J.C. Efeitos da ingestão de flúor provenientes do fosfato de rocha e fluoreto de sódio na fluorose dental de ovinos. 2007. 63f. Dissertação (Mestrado) - Faculdade de Zootecnia e Engenharia de Alimentos, Universidade de São Paulo, Pirassununga, SP.

KANECO, J.J. Thyroid function. In: KANECO, J.J.; HARVEY, J.W.; BRUSS, M.L. Clinical biochemistry of domestic animals. 5.ed. London: Academic, 1997. p.571-588.

KESSABI, M.; HAMLIRI, A.; BRAUN, J.P. Experimental fluorosis in sheep: alleviating effects of aluminum. Vet. Hum. Toxicol., v.28, p.300-304, 1986.

LARSEN, P.R.; DAVIES, T.F. Hypothyroidism and thyroiditis. In: LARSEN, P.R.; KRONENBERG, H.M.; MELMED, S. et al. Williams textbook of endocrinology. 10.ed. Philadelphia: Saunders, 2002. p.423-455.

LI, L. The biochemistry and physiology of metallic fluoride: action, mechanism and implications. Clin. Rev. Oral Biol. Med., v.14, p.100-114, 2003.

LIN-FA-FU, A.; ZHAO, H.X.; LIN, J. et al. The relationship of a low-iodine and high-fluoride environment to subclinical cretinism in Xinjiang. Iodine Def. Disorder Newsl., v.7, p.24-25, 1991.

LOPES, H.O.S. Fontes alternativas de fósforo para a redução de custos do sal mineral para bovinos. Planaltina: Embrapa Cerrado, 2001. 92p.

LUNA, L.G. Manual of histology staining methods of the Armed Forces Institute of Pathology. 3.ed. New York: McGraw Hill, 1968. 258p.

McDOWELL L.R. Minerals in animal and human nutrition. San Diego: Academic, 1992. 524p.

McDOWELL, L.R. Minerais para ruminantes sob pastejo em regiões tropicais, enfatizando o Brasil. São Paulo: UNESP, 1999. 93p. 
MAHMOOD BHAT, G.H. Effect of fluoride ions on the thyroid glands of guinea pigs. JK Pract. Int., v.3, p.94-96, 1996.

MARASLI, N. Estudies in serum tri-iodothyronine $\left(\mathrm{T}_{3}\right)$ and thyroxin $\left(\mathrm{T}_{4}\right)$ levels in normal sheep and sheep with fluorosis. Vet. Fak. Derg. Univ. Ankara, v.39, p.207-214, 1992.

NUTRIENT requirements of Domestic Animals: nutrient requirements of sheep. Washington: National Research Council, 1985, 99p.

REZENDE, M.J.M.; VELOSO, J.A.F.; TURCHETTI-MAIA, R.M.M. Effect of dietary fluoride from Araxá rock phosphate on the hepatic production cyclic-adenosine monophosphate in broilers. Arq. Bras. Med. Vet. Zootec., v.51, p.477484, 1999.

SAMAL, U.N.; NAIK, B.N. The fluorosis problem in tropical sheep. Fluoride, v.25, p.183-190, 1992.

SOLDIN, O.P. Controversies in urinary iodine determinations. Clin. Bioch., v.35, p.575-579, 2002.

SHUPE J.L. Clinicopathologic features of fluoride toxicosis in cattle. J. Anim. Sci., v.51, p.747-758, 1980.
SUSHEELA, A.K.; BHATNAGAR, M.; VIG, K. et al. Excess fluoride ingestion and thyroid hormone derangements in children living in Delhi, India. Fluoride, v.38, p.98-108, 2005.

SWARUP, D.; DWIVEDI, S.K.; DEY, S. et al. Fluoride intoxication in bovines due to industrial pollution. Indian J. Anim. Sci., v.68, p.605-608, 1998.

TEZELMANN, S.; SHAVER, J.K.; GROSSMAN, R.F. et al. Desensitization of adenylate cyclase in Chinese hamster ovary cells transfected with human thyroid-stimulating hormone receptor. Endocrinology, v.134, p.1561-1569, 1994.

WILLEM, S.C.; SANDE, J.B.V.; DUMONT, J.E. Inibition of thyroid secretion by sodium fluoride in vitro. Bioch. Bioph. Acta., v. 164, p. 197-204, 1972.

ZENGRONG, S.; FENGZHEN, L.; LI'NA, W. et al. Effects of high fluoride water on the cerebral function of mice. Fluoride, v.41, p.148-151, 2008.

ZHAO, W.; ZHU, H.; YU, Z. et al. Long-term effects of various iodine and fluorine doses on the thyroid and fluorosis in mice. Endocrinol. Regul., v.32, p.63-70, 1998 